\title{
Delivering Quality of Care while Managing the Interests of All Stakeholders
}

\author{
Andrea Stopper ${ }^{\mathrm{a}}$ Agnieszka Raddatz ${ }^{\mathrm{b}} \quad$ Aileen Grassmann $^{\mathrm{a}} \quad$ Stefano Stuard $^{\mathrm{a}}$ \\ Marcus Menzer ${ }^{\mathrm{a}}$ Gernot Possnien ${ }^{\mathrm{a}}$ Laura Scatizzi $^{\mathrm{a}}$ Daniele Marcelli ${ }^{\mathrm{a}}$ \\ ${ }^{\mathrm{a}}$ NephroCare Coordination and ${ }^{\mathrm{b}}$ International Strategic Development, Fresenius Medical Care, Bad Homburg, \\ Germany
}

\section{Key Words}

Balanced Scorecard $\cdot$ End-stage renal disease •

Kaizen approach $\cdot$ Managing complex organizations .

National healthcare system $\cdot$ Stakeholders

\begin{abstract}
National healthcare systems worldwide face growing challenges to reconcile interests of patients for high-quality medical care and of payers for sustainable and affordable funding. Advances in the provision of renal replacement therapy can only be made by developing and implementing appropriate sophisticated and state-of-the-art business models that include reimbursement schemes for comprehensive care packages. Such business models must succeed in integrating and reconciling the interests of all stakeholders. NephroCare as dialysis provider has adopted and tailored recognized management techniques, i.e. Balanced Scorecard and Kaizen, to achieve these goals. Success of the complete business model package is tangible - strategies initiated to improve treatment quality even at the cost of providers have been translated into win-win scenarios for the complete stakeholder community. Room for improvement exists: the possibility to extend the portfolio of service offerings within the comprehensive care frame, as well as the challenge for achieving a balance between the stability of targets while keeping these up to date concerning new insights.

Copyright $\odot 2011$ S. Karger AG, Base
\end{abstract}

\section{Introduction}

Current demographic and economic developments pose considerable challenges for European healthcare systems. Among these challenges, the costs of treatment for the growing population of chronically ill patients (including those requiring renal replacement therapy) are considered an emerging public health problem. Indeed, over the last decade, the prevalence of end-stage renal disease (ESRD) in Europe grew by an annual average rate of $5.3 \%$. By the end of 2010, the number of ESRD patients in Europe was estimated to be 642,000 and, of these, approximately 426,000 (around 66\%) received dialysis treatment [1].

All over Europe, care programs for these patients are mainly financed by public funds, which comprise either the statutory social security system or the national health system [2]. The state with its institutions not only finances the care but also sets the regulatory frame for public and private dialysis care providers: it formulates the objectives of renal care policy, defines the respective national legal norms and designs the model of care provision for dialysis. Through these competences and the political decision-making process, the state defines the environment of each national dialysis provision system. The four key stakeholders of this system are the patients, the shareholders (private or public owners of clinics and hospitals), the employees (predominantly the clinical staff) and the community of citizens.

\section{KARGER}

Fax +41613061234 E-Mail karger@karger.ch www.karger.com
Laura Scatizzi

NephroCare Coordination EMEA, Fresenius Medical Care Deutschland GmbH Else-Kröner-Strasse 1

DE-61352 Bad Homburg v.d.H. (Germany)

Tel. +49 6172609 5115, E-Mail laura.scatizzi@fmc-ag.com 
Because of the state's competence in setting the 'game rules', its understanding of 'optimal care' and its approach to quality is of substantial importance. No less important, however, is the state's perception of the affordability of the care and what service is necessarily required. Therefore, consideration of the quality issue by this stakeholder is typically relative to the availability of funds. The ongoing confrontation of the seemingly irreconcilable forces of growing patient demand and need of high quality standards, on the one hand, and constrained resources on the other hand, places the concept of efficiency in the center of the debate on the 'optimal' dialysis care. Currently, many healthcare systems in Europe try to address the growing budget pressures by savings. Savings alone, however, can provide relief to the challenged financial situation only to a very limited extent. In the long run, the present high level of care can only be preserved if it is possible to increase efficiency. Therefore, when searching for the 'optimal care' paradigm for dialysis patients, high efficiency is required in addition to high medical standards.

In Europe, a broad consensus exists regarding targets for best medical practice in renal care [3]. Concepts regarding how to achieve these targets in the most efficient way, however, vary significantly. The variety of solutions, reflected by different national models of renal care as well as ongoing reforms and recent reform proposals, suggest that the search for an optimum is still ongoing. Among the different proposals for combining the objectives of quality and efficiency, the comprehensive approach to renal care (i.e. a bundling of patient-care-related services and product offerings into a single reimbursement package) deserves special attention. In recent years, the synergetic potential of the integrated/comprehensive care concept became apparent: through the affiliation of medical, technological and organizational perspectives, both efficiency and quality gains could simultaneously be achieved.

A recent observation supports the hypothesis that company-run dialysis care networks are particularly well equipped for offering comprehensive care: while the share of patients in non-public dialysis care grew by an annual average rate of round $4 \%$ over the last decade, the share of patients that were cared for in company-run dialysis networks grew annually at an average rate of over $8 \%$. At the end of the year 2010, in total around 85,600 dialysis patients in Europe were cared for by companyowned care networks [1]. Another market observation is also of interest in this setting: the scarcer the resources available in the national healthcare, the higher the bun- dling of services related to dialysis or - in other words the higher the degree of consolidation of renal care in the direct responsibility of a single care giver [1].

'Optimal care' of dialysis patients is a concept going beyond the medical appropriateness and economic efficiency; rather, it requires additionally the ability of a successful integration and reconciling of all different stakeholder perspectives (i.e. patient, employee, community and shareholder) and adapting to a variety of specific local needs. This is the pivotal challenge faced by all providers of dialysis care.

\section{Managing Complex Organizations}

For over a century, economic and business administration sciences have focused on how to optimize the performances of target- or purpose-oriented social organizations. Hospitals (community or privately owned), companies, foundations and administrative territorial units are all examples of such organizations. A variety of aspects are of particular relevance to organizations managing chronic diseases. Epidemiology and the nature of the chronic disease itself make it mandatory for each approach to be long-term oriented, sustainable (both for patient and payer), to have a multilevel character (e.g. viewing patients both as individuals and as a population), and to be of a knowledge-based and multivariate nature (with numerous correlations). In addition, organizations with responsibility for managing chronic diseases always have multiple stakeholders [4] and need to have tools to appreciate the effects of today's actions on tomorrow's results. They are therefore typically, and ideally, continuous learning organizations.

Following its introduction during the late 1980s and its subsequent refinement, the Balanced Scorecard (BSC) is now recognized as being a very promising management tool that addresses all the aforementioned challenges as well as all stakeholders $[5,6]$. It allows the consideration of a very large number of variables by translating these into a few performance measures. These measures are a combination of financial indicators, which testify the value of past actions, and operational indicators, which reflect customer satisfaction, internal processes and continuous improvement of the organization. The basic idea of the BSC is to organize all performance measures along four different perspectives and to select performance measures and targets that correlate with the strategic objectives of the organization (table 1) [7,8]. In balancing the four different perspectives, the BSC becomes a power- 
Table 1. BSC - translating vision and strategy into performance measures and targets

\begin{tabular}{|c|c|c|c|}
\hline Perspectives & Strategic objectives & Performance measures & Targets \\
\hline \multirow[t]{4}{*}{1 Patient perspective } & \multirow[t]{2}{*}{ Strategic objective 1.1} & Performance measure 1.1.1 & Targets for performance measure 1.1.1 \\
\hline & & Performance measure 1.1.2 & Targets for performance measure 1.1.2 \\
\hline & \multirow[t]{2}{*}{ Strategic objective 1.2} & Performance measure 1.2.1 & Targets for performance measure 1.2.1 \\
\hline & & Performance measure 1.2 .2 & Targets for performance measure 1.2.2 \\
\hline \multirow[t]{4}{*}{2 Shareholder perspective } & \multirow[t]{2}{*}{ Strategic objective 2.1} & Performance measure 2.1.1 & Targets for performance measure 2.1.1 \\
\hline & & Performance measure 2.1 .2 & Targets for performance measure 2.1.2 \\
\hline & \multirow[t]{2}{*}{ Strategic objective 2.2} & Performance measure 2.2 .1 & Targets for performance measure 2.2.1 \\
\hline & & Performance measure 2.2 .2 & Targets for performance measure 2.2.2 \\
\hline \multirow[t]{4}{*}{3 Employee perspective } & \multirow[t]{2}{*}{ Strategic objective 3.1} & Performance measure 3.1.1 & Targets for performance measure 3.1.1 \\
\hline & & Performance measure 3.1 .2 & Targets for performance measure 3.1.2 \\
\hline & \multirow[t]{2}{*}{ Strategic objective 3.2} & Performance measure 3.2 .1 & Targets for performance measure 3.2.1 \\
\hline & & Performance measure 3.2 .2 & Targets for performance measure 3.2 .2 \\
\hline \multirow[t]{4}{*}{4 Community perspective } & \multirow[t]{2}{*}{ Strategic objective 4.1} & Performance measure 4.1.1 & Targets for performance measure 4.1.1 \\
\hline & & Performance measure 4.1.2 & Targets for performance measure 4.1 .2 \\
\hline & \multirow[t]{2}{*}{ Strategic objective 4.2} & Performance measure 4.2 .1 & Targets for performance measure 4.2 .1 \\
\hline & & Performance measure 4.2 .2 & Targets for performance measure 4.2 .2 \\
\hline
\end{tabular}

In healthcare organizations treating chronic diseases, the four perspectives can be considered to correspond to the four key stakeholders: the patient, the shareholder, the employee and the community.

Fig. 1. Strategy implementation. To ensure strategy implementation, different and precise targets must be defined over time and for the different stakeholders.

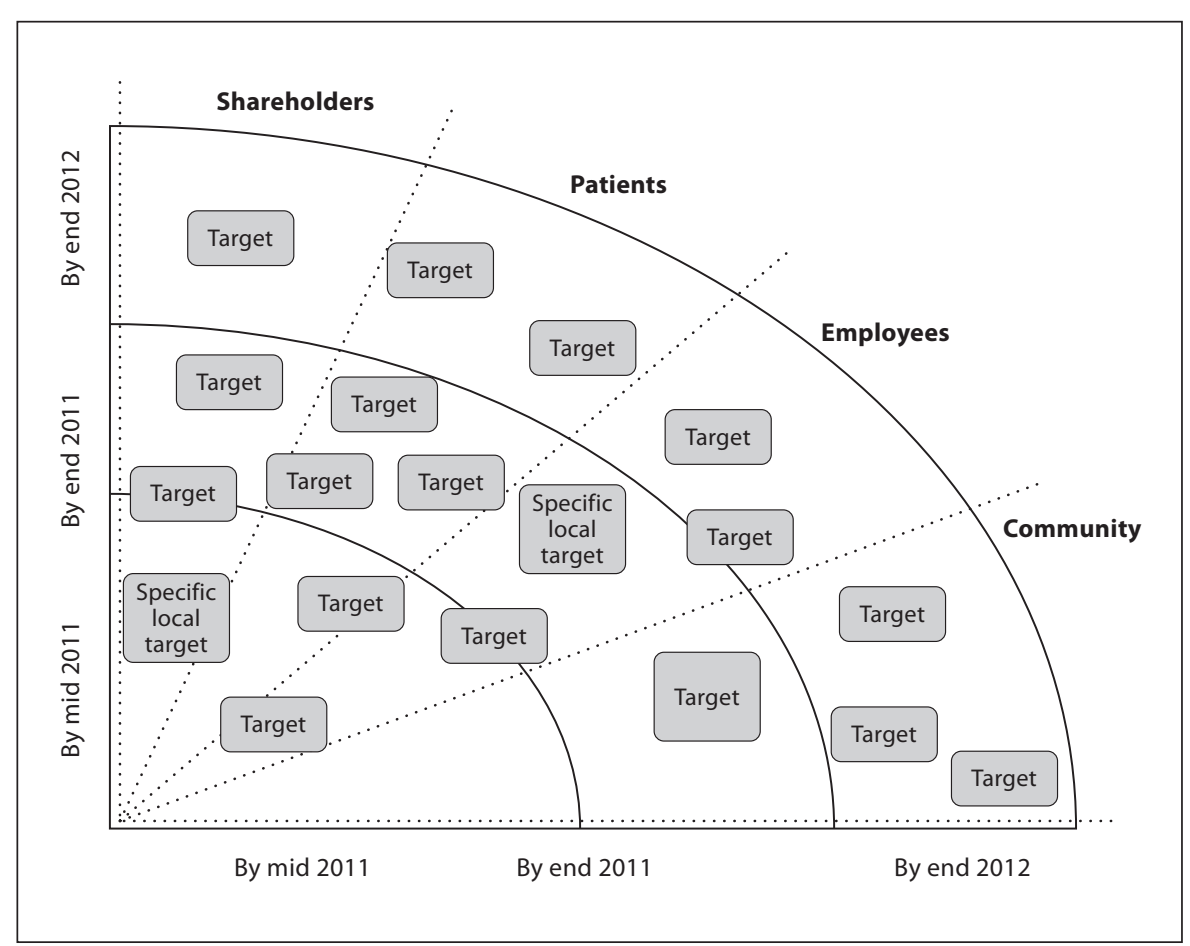


ful tool against suboptimization, while simultaneously ensuring focus on strategy as opposed to short-term orientation and control.

This long-term aspect is of crucial importance as it facilitates consideration of future developments and the execution of a sustainable therapeutical strategy at both patient and patient-population levels. Good results can be identified and achieved in line with the organization's strategy, and are closely correlated with the ability of the organization to build capabilities and to continuously develop and improve knowhow, processes, infrastructure and communication (fig. 1). These demands are integrally served by the BSC, which interlinks all stakeholders and supports knowhow development and diffusion through feedback, learning and education, thus giving a reliable framework for ensuring consistency of vision and action [8].

\section{The NephroCare Approach}

Fresenius Medical Care's approach to 'optimal care', based on the simultaneous integration of the perspectives of all stakeholders and a holistic therapy concept, is being applied in over 460 dialysis facilities in Europe where around 37,000 patients were treated at the end of 2010. Under the NephroCare umbrella name, the portfolio of care delivered to the patients includes the use of state-of-the-art dialysis products, renal pharmaceuticals and therapies (all of which are constantly being improved), as well as care from qualified, motivated clinic personnel who regularly receive further training. In every country of engagement, NephroCare adapts its care model to reflect the national healthcare architecture and to further develop concepts within the predefined regulative frame.

In order to achieve these objectives, NephroCare based its management processes on structured reports that allow for the cohesion of different care aspects. To meet the challenge of the reconciliation of the requirements of different care models within a single frame that allows for definition of universal best practices and targets, the management techniques BSC and Kaizen were applied. The application of such management methods and tools allows not only for continuous improvement, but also for internal benchmarking and integration of the interests of all involved stakeholders.

The strategic objectives in the NephroCare Balanced Scorecard (NC BSC) are based on the quality policy of Fresenius Medical Care. In total, nine strategic objectives
Table 2. The eight types of muda

\begin{tabular}{|c|c|c|}
\hline \multicolumn{2}{|c|}{ Muda } & \multirow{2}{*}{$\begin{array}{l}\text { Examples in dialysis centers } \\
\text { Mistakes in prescribing and delivering the } \\
\text { appropriate therapy }\end{array}$} \\
\hline 1 & Defects & \\
\hline 2 & Overproduction & $\begin{array}{l}\text { For example, that of ultrapure water and } \\
\text { dialysate }\end{array}$ \\
\hline 3 & Inventory & Inaccurate capacity planning and forecasting \\
\hline 4 & Motion & $\begin{array}{l}\text { Unnecessary movement of people, e.g. } \\
\text { because equipment or material was placed } \\
\text { where space was available }\end{array}$ \\
\hline 5 & Waiting & $\begin{array}{l}\text { Idle time for patients or employees resulting } \\
\text { from material, information, equipment, etc. } \\
\text { that is not ready }\end{array}$ \\
\hline 6 & Transportation & $\begin{array}{l}\text { Suboptimal transportation of dialysis } \\
\text { disposables and machines inside the dialysis } \\
\text { center }\end{array}$ \\
\hline 7 & Overprocessing & $\begin{array}{l}\text { Overachieving therapeutical targets to } \\
\text { increase the average of the center }\end{array}$ \\
\hline 8 & $\begin{array}{l}\text { Underutilization } \\
\text { of personnel } \\
\text { resources }\end{array}$ & $\begin{array}{l}\text { Physicians puncturing patients, dialysis } \\
\text { nurses cleaning machines, etc. }\end{array}$ \\
\hline
\end{tabular}

are aligned to the four perspectives (two to three strategic objectives per perspective) (see table 1 for example of structure). The patient perspective is the most important part of the NC BSC. The two strategic objectives within this perspective are the increase of life expectancy and the improvement of the quality of life of patients treated within the NephroCare network. The selected performance measures focus on process indicators describing how well the dialysis process has been performed as well as on outcome indicators specifying the actual clinical status of the patient. The two objectives of the employee perspective are to bind qualified personnel and to promote their professional development. Therefore, the corresponding performance measures focus on human resource management. The two objectives of the shareholder perspective are the continuous development of the company and attractive returns for its shareholders; performance measures relate to well-established management processes and financial controls. Finally, the three objectives for the community perspective are the upholding of various social responsibilities, the following of all legal and regulatory requirements and safety standards, and the contribution to the maintenance of the environment. The corresponding performance measures are het- 
Fig. 2. The Kaizen approach to problem solving.

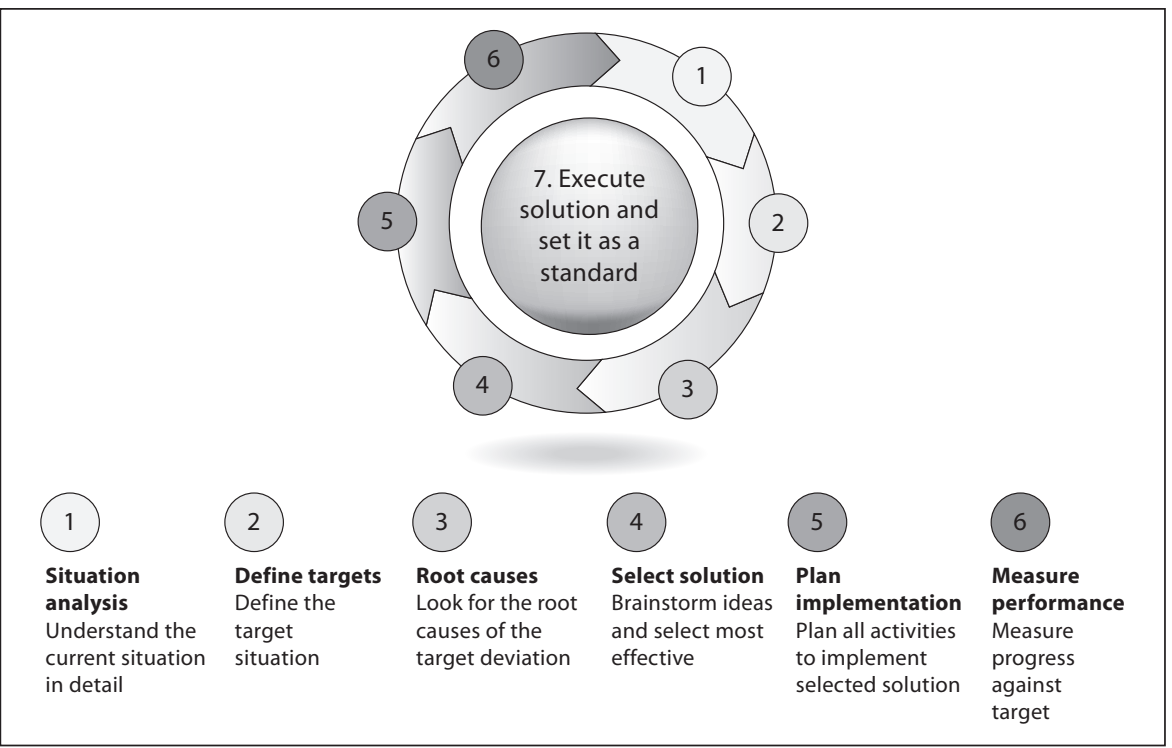

erogeneous, including performance indicators for the minimization of accidents to employees, for achievement of ISO certification, and for the reduction of water, electricity and waste [9].

To support NephroCare country organizations and indeed each single dialysis center in reaching the strategic objectives, the Kaizen methodology was introduced to dialysis centers. Kaizen is based on the Japanese philosophy of lean management and has been successfully applied to the delivery of healthcare [10]. In general, Kaizen is a methodology of continuous, incremental improvement to create more value for all stakeholders by identifying and eliminating non-value-adding activities (socalled muda, see table 2) [11].

Even if Kaizen usually only delivers small incremental improvements for less complex and tangible 'shop floor' problems, the sum of continual aligned small improvements yields large results in the form of compound quality and productivity improvements. In its essence, Kaizen targets the establishment of a culture of continuous quality improvement. A core principle of Kaizen is the involvement of all employees working in the affected area in the detection of improvement potentials, the generation of ideas for solution, and the implementation of such in a teamwork approach. The application of Kaizen in NephroCare dialysis centers is closely linked with improving performance as measured with the NC BSC. Each target deviation triggers the management of a dialysis center to invite the employees to apply the systematic Kaizen approach of problem solving (fig. 2).
The scope of improvements achieved by applying Kaizen at NephroCare dialysis centers is comparable to the NC BSC: this ranges from medical indicators to efficiency gains, and even to environmental protection measures, e.g. reduction of waste generation per treatment.

\section{Example of a Balanced Scorecard Application}

In order to illustrate a scenario as a base for discussion, the results of the patient perspective of the NC BSC of a center recently acquired in an Eastern European Country are taken as an example (fig. 3a). At the time of acquisition (early 2008), this center was managing 186 patients, more than $80 \%$ of the patients had a native fistula for vascular access, and the level of anemia correction was good, with more than $80 \%$ of patients on target (which is often not the case in countries with limited resources). On the negative side, the hospitalization rate was not satisfactory, being in the range of 25-35 days per patient-year. After the acquisition, NephroCare introduced a modality of higher dialysis efficacy, carrying the higher associated costs. After just 6 months, $60 \%$ of the patients were treated on this modality. Accordingly, an improved removal of middle molecular weight toxins can be considered achieved [12], and the percentage of patients reaching eKt/V targets increased in parallel (98 vs. $63 \%$ in May 2008). After 1.5 years, a decrease in the hospitalization rate was observed, with the final rate being less than 15

Blood Purif 2011;32:323-330 
Fig. 3. Example of a NC BSC application for the patient perspective. a The achievement of predefined targets (see below) for five performance measures is displayed. All patients were treated in a dialysis center in Eastern Europe that was acquired in May 2008 (then managing 186 patients); the development to January 2011 is shown (ending with 287 patients). b The same performance measures are reported here for the sum of all NephroCare clinics in a Western European country. The number of patients increased from 1,349 in June 2005 to 1,730 by January 2011 . $\mathrm{Hb}=\mathrm{He}-$ moglobin (target is $100 \%$ of patients having levels $\geq 10$ and $\leq 13 \mathrm{~g} / \mathrm{dl}$ ); On-line $\mathrm{HDF}=$ on-line hemodiafiltration (target is $100 \%$ of patients treated by this modality); $\mathrm{AVF}=$ arteriovenous fistula (target is 100\% of patients having this form of vascular access); eKt/V = equilibrated Kt/V (target is $100 \%$ of patients on three times weekly dialysis having $\geq 1.2$ ); Patient at risk of hepatitis $\mathrm{B}=$ defined in HbsAg-negative patients as the absence of $\mathrm{Hbc} \mathrm{Ab}$ or $\mathrm{Hbs} \mathrm{Ab}$ $<10 \mathrm{UI} / \mathrm{l}$ (target is $0 \%$ patients at risk).
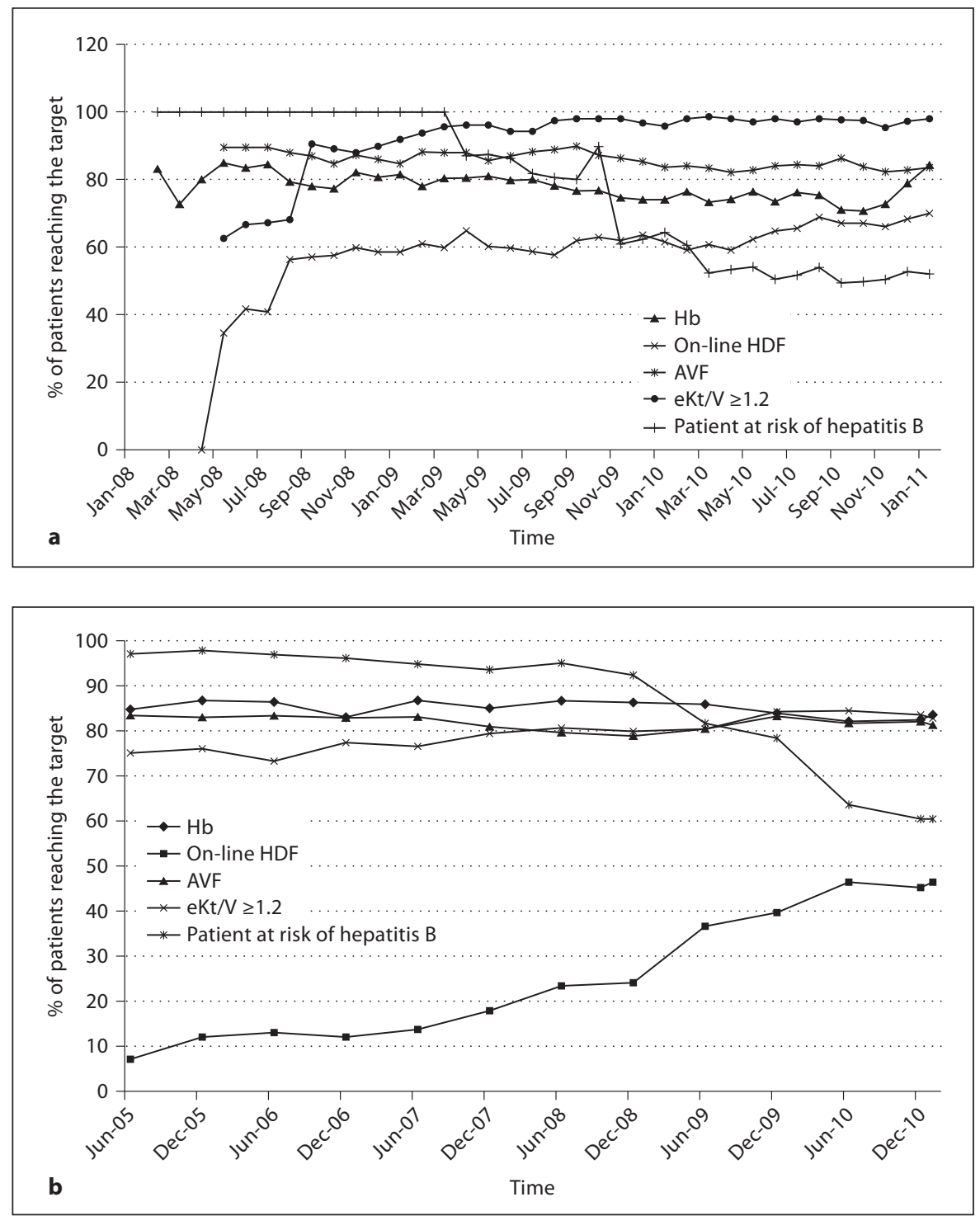

days per patient-year. Even though a causative effect cannot be stated, a relationship between an improvement measure applied for more than 18 months and the outcome hospitalization has to be stressed, especially given the absence of any relevant change of the composition of the treated population (the proportion of elderly and diabetic patients increased from 10.2 to $15.1 \%$ and from 7.5 to $13.2 \%$, respectively) and of the reimbursement system for hospitalization in place in the country. Finally, a progressive reduction of patients at risk for hepatitis B was observed (100\% in February 2008, 52\% in January 2011). Similar trends were detected from an analysis of a homogeneous group of clinics in a Western European country: figure $3 \mathrm{~b}$ shows the cumulative re- sults for these NephroCare clinics (where the total number of patients treated was 1,349 in 2005 and rose to 1,730 by January 2011).

\section{Discussion}

Managing complex organizations like dialysis clinic networks goes beyond the achievement of pure medical targets - when done in an effective and sustainable manner, the varied interests of all stakeholders are served. Management tools such as the BSC and Kaizen have proved to be effective in meeting these and multiple other demands on such organizations. 
Table 3. Steps to help avoid pitfalls in the application of a BSC

\begin{tabular}{ll}
\hline $\begin{array}{l}\text { Develop a } \\
\text { strategy-driven } \\
\text { model }\end{array}$ & $\begin{array}{l}\text { Transform the strategic plan into a roadmap } \\
\text { and develop a causal model based on its } \\
\text { hypothesis }\end{array}$ \\
\hline Validate data & $\begin{array}{l}\text { Use statistical analysis and qualitative analysis } \\
\text { techniques to test and validate the model }\end{array}$ \\
\hline $\begin{array}{l}\text { Continuous } \\
\text { model evaluation } \\
\text { and development }\end{array}$ & $\begin{array}{l}\text { Regular management review sessions will } \\
\text { challenge validity of performance measures } \\
\text { for strategy implementation }\end{array}$ \\
\hline $\begin{array}{l}\text { Base actions on } \\
\text { findings }\end{array}$ & Be consistent \\
\hline $\begin{array}{l}\text { Decide most } \\
\text { appropriate }\end{array}$ & $\begin{array}{l}\text { Knowledge-based organizations have to } \\
\text { actions }\end{array}$ \\
\hline $\begin{array}{l}\text { Verify and validate } \\
\text { become learning organizations }\end{array}$ & $\begin{array}{l}\text { Analyze deviations of scores from targets and } \\
\text { assess effectiveness and efficiency of actions }\end{array}$ \\
\hline
\end{tabular}

In the case of application of the BSC, a number of key success factors should be considered. Developing and implementing a BSC is a change management process that involves the entire organization; it is not simply the task of defining and establishing a set of performance measures. It means stopping usual activities and starting to live the organization's vision and mission through the continuous implementation of its strategy. A responsible and accountable person has to be defined for each selected performance measure. This will avoid one of the most common mistakes, i.e. measuring performance instead of managing performance. Managing performance means understanding performance measures as dynamic projects or programs. Following regular review of the actual scores, appropriate initiatives or corrective actions are taken.

Performance measures in a successful learning organization tend to reach saturation and lose importance as strategy implementation drivers. Therefore, they need to be regularly revised and substituted by new measures to drive the organization to new levels of performance. The 'proportion of patients on HDF' is an example of a NephroCare performance measure that required adjustment as new evidence became available: after the publication of the study of Canaud et al. [13], it became clear that it is necessary to include also the volume of reinfusion fluid in post-dilution hemodiafiltration. The complexity of the model suggests that modern techniques such as computational intelligence or the use of neural networks could be useful. Although design and planning have to stay in appropriate relation to the implementation phase, strat- egy execution is the real premium of a BSC approach. This can be achieved through alignment and consistent development between incentive reward systems and performance [14].

The BSC also has some limits. It is basically a model describing how to put vision and mission of an organization into effect through implementation of a strategy and presents two types of possible mistakes: (1) wrong or inadequate model design and definition, and (2) wrong or inadequate implementation. Critics have also underlined the lack of really argumentative concepts to link propositions [15] and missing validation of cause and effect relationships [16]. These are risks similar to those existing when working with quality or key performance indicators - lack of continuous improvement is possibly related to the wrong selection of indicators, lack of understanding of cause-effect relations and their time-related evolution as well as to wrong decisions about improvement actions [17]. Table 3 outlines necessary steps that must be undertaken to avoid these pitfalls.

Very often, service providers operating in a complex system like the healthcare system try to maximize efficiency by focusing on particular tasks. Accordingly, some cost-saving procedures can be implemented by one player that create disproportionally higher costs for another player. This is not the case here - in fact the opposite is true: the dialysis provider improved treatment at its own cost, thereby producing a saving for the payer and, in addition, avoiding part of the sufferance related to hospitalization for the patients. At least two stakeholders (patients, the community) benefit from such an improvement measure. Moreover, we believe that the benefit to the shareholder is significant, and can even exceed the extra costs carried by the provider. Firstly, lower hospitalization means better deployment of staff and infrastructures. When a patient is hospitalized, the provider is spared the cost of the disposables but many fixed costs remain (e.g. staff, amortization of investments, cleaning, air-conditioning, etc.). Ideally, the higher quality of life experienced by the patient through avoiding hospitalization would in itself advertise the attractiveness of the provider clinic. The same is true for measures applied in order to increase the proportion of patients protected against hepatitis $B$. Despite the application of strict hygiene rules, the risk of infection is not negligible (particularly in countries where the prevalence of hepatitis B is still significant). Therefore, a higher focus on an effective vaccination plan could produce positive results for all stakeholders.

Catheters and grafts represent weak points, not only for different national health systems in terms of the in- 
creased cost related to access generation and increased patient morbidity, but also for the patients themselves (discomfort, increased morbidity and mortality). Increasingly higher numbers of patients start dialysis with catheters, and the waiting time to obtain arteriovenous fistulas (AVFs) is progressively increasing $[18,19]$. Nevertheless, AVFs are widely accepted as the preferred hemodialysis vascular access type. They are associated with better survival and a lower incidence of complications compared to permanent catheters and arteriovenous grafts. Moreover, indirect costs related to AVFs are lower: it is accepted knowledge that significantly higher doses of erythropoietin are required to reach target hemoglobin levels in patients with permanent catheters compared to patients with AVFs [20]. Extending the services included in the bundle to cover also AVF provision and care for chronic kidney disease stage IV-V patients would appear to be in the interest of all stakeholders. Indeed, this has just recently been included in the Portuguese reimbursement bundle.

The bundling of care for dialysis patients into 'one hand' - if properly applied - has several advantages: it enables the implementation of scale efficiencies that reduce costs, allows for innovation and supports the incen- tives to maintain a patient-centric focus. Thus, the comprehensive approach benefits not only the patients but also the national healthcare systems because of a better cost predictability and a better coordination of care, as well as reduction of total cost of care for the ESRD patient population. In particular, the reduction of inpatient care as a result of the high quality standards provided to dialysis patients in ambulatory care can be seen as a significant cross-sectional benefit for all stakeholders.

In conclusion, the quality in the NephroCare approach is not only the degree of complying with predefined measures, but an ongoing process of assessing and anticipating the needs of its patients together with all other stakeholders. This is supported by the potential to closely analyze large patient databases with respect to the complete therapy provided, and subsequently offer solutions more in tune with the needs of the whole stakeholder community. Accordingly, the approach starts with the business model based on assessment, followed by continuous improvement and innovation. In this understanding, NephroCare works on the further development of objectives through research and development, as well as employment of measures and tools for monitoring, achieving and surpassing existing targets.

\section{References}

1 Fresenius Medical Care Market \& Competitor Survey 2010. Company research, unpubl data, 2010.

$\checkmark 2$ Lameire N, Joffe P, Wiedemann M: Healthcare systems - an international review: an overview. Nephrol Dial Transplant 1999; 14(suppl 6):3-9.

-3 Tattersall J, Martin-Malo A, Pedrini L, Basci A, Canaud B, Fouque D, Haage P, Konner K, Kooman J, Pizzarelli F, Tordoir J, Vennegoor M, Wanner C, ter Wee P, Vanholder R: EBPG guideline on dialysis strategies. Nephrol Dial Transplant 2007;22(suppl 2):ii5-ii21.

$\checkmark 4$ Lewis R, Dixon J: Rethinking management of chronic diseases. BMJ 2004;328:220-222.

5 Schneidermann AM: The first balanced scorecard: analog devices, 1986-1988. J Cost Manage 2001:16-26.

6 Kaplan RS, Norton DP: The balanced scorecard - measures that drive performance. Harv Bus Rev 1992;70:71-79.

7 Kaplan RS, Norton DP: Putting the balanced scorecard to work. Harv Bus Rev 1993:134147.

8 Kaplan RS, Norton DP: Using the balanced scorecard as a strategic management system. Harv Bus Rev 1996:75-85.
>9 Stopper A, Amato C, Gioberge S, Giordana G, Marcelli D, Gatti E: Managing complexity at dialysis service centers across Europe. Blood Purif 2007;25:77-89.

10 Going Lean in Health Care. IHI Innovation series white paper. Cambridge/MA, Institute for Health Care Improvement, 2005.

11 Eaton M: Lean for Practitioners - An Introduction to Lean for Healthcare Organisations. New York, Academy Press, 2008.

12 Locatelli F, Gauly A, Czekalski S, Hannedouche T, Jacobson SH, Loureiro A, Martin-Malo A, Papadimitriou M, PasslickDeetjen J, Ronco C, Vanholder R, Wizemann V: The MPO Study: just a European HEMO Study or something very different? Blood Purif 2008;26:100-104.

$\checkmark 13$ Canaud B, Chenine L, Henriet D, Leray H: Online hemodiafiltration: a multipurpose therapy for improving quality of renal replacement therapy. Contrib Nephrol. Basel, Karger, 2008, vol 161, pp 191-198.

14 Rohm H, Halbach L: A balancing act: sustaining new directions. Perform 2004;3:1-8.

taining new directions. Perform 2004;3:1-8.
Norreklit H: The balanced scorecard: What is the score? A rhetorical analysis of the balanced scorecard. Account Organ Soc 2003; 28:591-619.
$>16$ Ittner CD, Larcker DF: Coming up short on nonfinancial performance measurement. Harv Bus Rev 2003;81:88-95, 139.

17 Ponce P, Galego V, David MI, Conceiçao N: How do we react to quality indicator targets and how relevant are our efforts? Port J Nephrol Hypertens 2010;165-171.

18 Rayner HC, Pisoni RL, Gillespie BW, Goodkin DA, Akiba T, Akizawa T, Saito A, Young EW, Port FK: Creation, cannulation and survival of arteriovenous fistulae: data from the Dialysis Outcomes and Practice Patterns Study. Kidney Int 2003;63:323-330.

19 Ethier J, Mendelssohn DC, Elder SJ, Hasegawa T, Akizawa T, Akiba T, Canaud BJ, Pisoni RL: Vascular access use and outcomes: an international perspective from the Dialysis Outcomes and Practice Patterns Study. Nephrol Dial Transplant 2008;23:32193226.

20 Goldstein SL, Ikizler TA, Zappitelli M, Silverstein DM, Ayus JC: Non-infected hemodialysis catheters are associated with increased inflammation compared to arteriovenous fistulas. Kidney Int 2009; 76: 1063-1069. 